\section{The factorial structure of responses to perceptual complexity}

\author{
DAVID R. EVANS, University of Calgary, Calgary, Alta., Canada \\ and \\ H. I. DAY, Ontario Institute for Studies in Education, Toronto, Ont., Canada
}

A series of figures differing in complexity were exposed to 44 nursing students. Ss were monitored for GSR and heart rate while they looked at each figure for as long as they wished. They then rated each figure on 20 semantic differential-type scales. The data were factor analyzed by the principal axis method, with communalities iterated by refactoring followed by varimax rotation. Four factors were extracted and the first three were identified as Osgood's activity, evaluative, and potency factors. It was suggested that the activity factor relates to arousal-raising stimulus properties, while the evaluative factor relates to arousal-reducing or -restraining stimulus properties.

There has recently been a proliferation of studies showing that complexity of visual displays may affect a number of exploratory as well as verbal responses of affect. Complexity of visual pattern has been shown to affect looking time (Berlyne, 1957; Day, 1966, 1968b), GSR indices (Berlyne, Craw, Salapatek, \& Lewis, 1963), ratings of interestingness and pleasingness (Berlyne, 1963; Day, $1967 \mathrm{~b}, 1968 \mathrm{c})$, expressions of liking (Berlyne \& Lawrence, 1964), and semantic differential-type scales (Berlyne \& Peckham, 1966). While there has been considerable speculation regarding the interrelationship among these responses (Berlyne, 1963; Berlyne \& Peckham, 1966; Day, 1968b), thus far no study has examined systematically this interrelationship with stimuli at different levels of complexity. The present study was therefore designed to incorporate all of these responses within Ss and to examine the factor structure of the subjective responses to perceptual complexity.

\section{SUBJECTS}

Forty-four female nursing students voluntarily participated in the experiment. They were lested in individual sessions.

\section{APPARATUS}

In the first part of the experiment, a set of $2 \times 2$ in. slides of 11 randomly designed black-on-white solid polygons, differing in number of sides from 4 to 90 , were used $(4-, 6 \cdot, 10-$, $14-, 20-, 28-, 34-, 40-, 54-, 70-$, and 90 -sided figures). The slides were projected by a Kodak Carousel projector to fill a $30 \times 30$ in. screen. A balanced Latin square design (Edwards, 1960, p. 275) was used to control for the effects of exposure to previous figures on exposure to succeeding figures. Ss were first exposed to a sample figure of 46 sides, followed by the 11 figures in one of 22 orders. Ss were assigned randomly to view the figures such that two Ss viewed the figures in each order.

Heart rate and GSR were recorded for each S. Electrodes were placed on the upper inside surface of each forearm to measure heart rate. The signal from these electrodes was monitored by means of a cardiotachometer coupler in one channel of a two-channel Beckman Dynograph. GSR electrodes were placed on the palm and dorsal surface of the right hand. The GSR was monitored by means of a Beckman GSR coupler in the other channel of the Dynograph. A ground electrode from the ground terminal of the Dynograph was placed on the left posterior surface of the S's neck.

Booklets were prepared with a print of each figure and 20 semantic differential scales on each page. Two booklets were collated for each of the 22 orders. The 20 semantic scales were those used by Day (1967a), but the scale of hot-cold was dropped and the scales of complex-simple and likable-dislikable were added.

\section{PROCEDURE}

The electrodes were attached to $\mathrm{S}$ on arrival and allowed to polarize for $15 \mathrm{~min}$ or until the basal skin resistance was less than 200,000 ohms. Then $S$ was given the following instructions: "You are going to see a series of geometrical figures. I would like you to look at each figure as long as you wish. When you do not wish to look at the figure any longer please press the button and the figure will go off the screen. Then there will be a 30 -second pause and the next figure will appear." The onset and offset of each figure was recorded by an event pen on the Dynograph.

When $S$ had viewed all the figures, the electrodes were removed. $\mathbf{S}$ was handed a pencil and a booklet of figures in the order that she had viewed them and was required to rate each figure on each of the 20 semantic differential scales.

\section{RESULTS}

The average mean maxima (Opton, Rankin, \& Lazarus, 1966) heart rate for each $S$ in response to each figure was computed. The average GSR amplitude in log (conductance $x$ 1,000 ) for each $S$ in response to each figure was computed. The length of time in seconds each $\mathrm{S}$ viewed each figure was recorded. The response measures for each $S$ to each figure, then, were ratings on each of the 20 semantic scales, looking time, GSR, and heart rate.

The mean response measure to each figure was computed and a 23 by 11 matrix formed, i.e., measures by figures. One further variable, the number of sides of each figure, was added to this matrix as a marker variable to form a 24 by 11 matrix. From this matrix, a matrix of intermeasure correlations was computed. This was analyzed by the principal axis method as described by Harman (1960). The principal axis method was then repeated with the communalities obtained in the previous solution in the diagonal of the matrix of intermeasure correlations. This latter step was repeated until each of the recomputed communalities converged with each of the preceding communalities to within plus or minus .005. Orthogonal rotation by varimax method was then carried out with unity for eigen values (Kaiser, 1958). The factor loadings for each of the response measures on the resultant four factors are shown in Table 1.

On the basis of the results reported by Osgood, Suci, \& Tannenbaum (1957, pp. 36-39), the first three factors are readily labeled. The first factor can be identified as "activity" by the measures which have high loadings on it: passive-active (.88), relaxed-tense (.79), and calming-exciting (.88). The second factor can be identified as "evaluative" by those measures having high loadings on it: good-bad (.95), ugly-beautiful $(-.91)$, and pleasing-displeasing ( .97$)$. Similarly, the third factor can be identified as the "potency" factor by those measures with high loadings on it: small-large (.91) and weak-powerful (.82). The fourth factor appears to represent primarily the heart-rate response, and thus may be considered a unique factor.

\section{DISCUSSION}

The factors extracted by Osgood, Suci, \& Tannenbaum (1957) occurred in the following order: evaluative, potency, and activity. In the present experiment, however, the factors were as follows: activity, evaluative, and potency. This is consistent with the observation of Osgood, Suci, \& Tannenbaum (1957) that when 
Table 1

Rotated Factor Loadings of Responses to Perceptual Complexity

\begin{tabular}{|c|c|c|c|c|c|}
\hline \multirow[b]{2}{*}{ Responses } & \multicolumn{5}{|c|}{ Factor } \\
\hline & I & II & III & IV & $h^{2}$ \\
\hline Hard-Soft & .03 & -.07 & -.63 & .62 & .78 \\
\hline Definite-Uncertain & .94 & .17 & -.29 & .06 & .99 \\
\hline Sharp-Dull & -.18 & .42 & -.71 & .46 & .93 \\
\hline Sick-Healthy & -.75 & -.45 & .26 & .10 & .85 \\
\hline Pleasing-Displeasing & .11 & .97 & -.10 & .07 & .96 \\
\hline Weak-Powerful & .18 & -.05 & .82 & -.18 & .74 \\
\hline Small-Large & .01 & -.16 & .91 & .34 & .98 \\
\hline Complex-Simple & -.97 & .18 & -.12 & -.03 & .99 \\
\hline Interesting-Boring & -.85 & .48 & -.14 & -.05 & .97 \\
\hline Calming-Ex citing & .88 & -.10 & .45 & -.09 & .99 \\
\hline Ugly-Beautiful & .33 & -.91 & -.02 & -.10 & .94 \\
\hline Deep-Shallow & -.87 & .17 & -.40 & .02 & .94 \\
\hline Passive-Active & .88 & -.31 & .28 & -.00 & .96 \\
\hline Happy-Sad & -.33 & .77 & -.32 & -.02 & .81 \\
\hline Rough-Smooth & -.96 & .15 & -.11 & .16 & .99 \\
\hline Good-Bad & .11 & .95 & .13 & .06 & .93 \\
\hline Hazy-Clear & -.91 & -.07 & .21 & -.26 & .94 \\
\hline Meaningful-Meaningless & -.41 & .86 & -.23 & -.14 & .98 \\
\hline Relaxed-Tense & .79 & .13 & .41 & -.30 & .89 \\
\hline Likeable-Dislikeable & -.07 & .96 & -.10 & .08 & .94 \\
\hline Looking Time & .94 & -.26 & .07 & .05 & .95 \\
\hline Heart Rate & -.10 & .11 & -.00 & .85 & .74 \\
\hline GSR & .89 & -.08 & .14 & -.17 & .85 \\
\hline Number of Sides & .87 & -.27 & -.03 & -.22 & .87 \\
\hline Percent of Total Variance & 49 & 22 & 12 & 6 & 89 \\
\hline
\end{tabular}

aesthetic objects (paintings) are measured, the activity factor becomes more prominent. The measures which have high loadings on this activity dimension are definite-uncertain, simple-complex, smooth-rough, clear-hazy, looking time, GSR, and passive-active. Measures with high loadings on the evaluative factor are pleasing-displeasing, beautiful-ugly, good-bad, and likable-dislikable. The two measures which have high loadings on the potency factor are small-large and weak-powerful.

Berlyne (1963) notes that a basic assumption of his theory of collative motivation is that perceptual complexity affects arousal. He suggests that ratings of interestingness are related to changes in arousal produced by increases in perceptual complexity. Berlyne \& Peckham (1966) have noted the similarity in the effects of perceptual complexity on ratings of interestingness and slow-fast, representing Osgood's activity dimension. Thus, as would be predicted, the response measures of change in GSR and interesting-boring load highly on the activity factor in the present experiment.

On the other hand, Berlyne (1963) postulates that ratings of pleasingness are related to arousal-restraining stimulus properties. Berlyne \& Peckham (1966) have drawn attention to the similarity of effects of perceptual complexity on ratings of pleasingness and Osgood's evaluative factor represented by ugly-beautiful. The present results confirm the observations of Berlyne (1963) and
Berlyne \& Peckham (1966) in that both the ugly-beautiful and the pleasing-displeasing ratings loaded highly on the evaluative factor, whereas neither GSR nor heart rate loaded highly on the II factor.

The results of the study by Berlyne \& Peckham (1966) suggest that the effect of increases in perceptual complexity has differential effects on measures representing the activity factor and measures representing the evaluative factor. Selecting those measures having the highest loading on each factor in the present experiment, the activity factor increased over perceptual complexity, while the evaluative factor decreased. It is probable, then, that the activity dimension has to do with the arousal-raising properties of a stimulus, while the evaluative factor relates to arousal-reducing or arousal-restraining stimulus properties. This interpretation would agree with the growing number of studies that have demonstrated that, as perceptual complexity increases, ratings of interestingness continue to increase, decrease (Slankis, 1965; Day, 1968c).

Day (1967b, 1968a) has been concerned with the relationship among the evaluative ratings of "liking," "interesting," and "pleasing" and has shown that the latter two are semantically and behaviorally different. He has posited that the term "liking" is more often comparable with pleasing than with interesting. This suggestion is confirmed by the loadings in this study. whereas ratings of pleasingness

Day has also suggested that free looking time is strongly related to complexity and interest in the figures rather than in their pleasingness (Day, $1968 \mathrm{~b})$. This evaluative concept seems to be related to evaluations of beautiful but not complex or tension-producing qualities of the figures. Looking time, which has been shown to increase with complexity (cf. Day, 1966, 1968b), seems to be strongly related to amplitude of GSR.

The heart-rate response was found to be unrelated to the three other factors. The reason for the uniqueness of this response should be sought in Lacey's postulate (Lacey, 1967) that heart-rate acceleration is dependent upon the type and complexity of stimulation presented and whether the $S$ tends to accept or reject the stimulation (Day, 1970). Individual differences in attitude to complexity must certainly be effective in determining cardiac reactivity.

\section{REFERENCES}

BERLYNE, D. E. Conflict and information-theory variables as determinants of human perceptual curiosity. Journal of Experimental Psychology, 1957, 53, 399-404.

BERLYNE, D. E. Complexity and incongruity variables as determinants of exploratory choice and evaluative ratings. Canadian Journal of Psychology, 1963, 17, 274-290.

BERLYNE, D. E., CRAW, M. A. SALAPATEK, P. H., \& LEWIS, J. L. Novelty, complexity, incongruity, extrinsic motivation and the G.S.R. Journal of Experimental Psychology, $1963,66,560-567$.

BERLYNE, D. E., \& LAWRENCE, G. H. Effects of complexity and incongruity variables on G.S.R., investigatory behaviors, and verbally expressed preference. Journal of General Psychology, 1964, 71, 21-45.

BERLYNE, D. E., \& PECKHAM, S. The semantic differential and other measures of reaction to visual complexity. Canadian Journal of Psychology. 1966. 20, 125-135

DAY, $\mathrm{H}$. Looking time as a function of stimulus variables and individual differences. Perceptual \& Motor Skills, $1966,22,423-428$.

DAY, H. A subjective definition of complexity. Perceptual \& Motor Skills. $1967 a, 25,583-584$.

DAY, H. Evaluations of subjective complexity, pleasingness and interestingness for a series of random polygons varying in complexity. Perception \& Psychophysics, 1967b, 2, 281-286.

DAY H. Preference: Interest or pleasure? Paper presented at the Annual Meeting of the Canadian Psycholoigcal Association, Calgary, $1968 \mathrm{a}$.

DAY H. Some determinants of looking time under different instructional sets. Perception \& Psychophysics, 1968b, 4, 279-281.

DAY $H$. The importance of symmetry and complexity in the evaluation of complexity, interest, and pleasingness. Psychonomic Science, 1968c, 10 , 339-340.

DAY $H$. The measurement of specific curiosity. Paper read at Symposium on Intrinsic Motivation in Education, Toronto, June 1970 . 
EDW psychological research. New York: Holt Rinehart \& Winston, 1960.

HARMAN, H. Modern factor analysis. Chicago: University of Chicago Press. 1960 .

KAISER. H. F. The varimax criterion for analytic rotation in factor analysis. Psychometrika, 1958, 23, 187-200.

LACEY,J. I Somatic response patterning and stress: Some revisions of activation theory. In M. H. Appley and R. Trumbul (Eds.), Psychological stress: Issues in

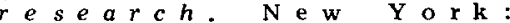
Appleton-Century-Crofts, 1967.
OPTON, E.. JR., RANKIN, N. O., \& LAZARUS, R. S. A simplified method of heart rate measurement. Psychophysiology, 1966, 2, 87-97.

OSGOOD C. E., SUCI G. J., \& TAN NENBAUM, $\mathrm{p}$. H. The measurement of meaning. Urbana, Ill: University of Illinois Press, 1957.

SLANKIS, I. V. The relations between verbal judgements of pleasingness and choice behavior, and between verbal judgements of interestingness and exploration time. Unpublished MA thesis, University of Toronto, 1965.

\section{Human operant eyelid conditioning: Auditory vs visual reinforcing signal*}

\author{
DONALD A. SCHUMSKY, JOHN TRINDER $\dagger$, and CHARLES L. RICHMAN $\dagger \dagger$ \\ University of Cincinnati, Cincinnati, Ohio 45221
}

The human eyeblink response was conditioned as a free operant, employing a double-blind yoked-control procedure. High levels of conditioning were obtained with experimental Ss by employing either a visual or auditory reward signal. No significant differences in response level were associated with reward signal modality in conditioning nor, as previously hypothesized, for yoked controls. Evidence for a significant conditioning effect was obtained even when the data of only "unaware" Ss were considered.

In a previous paper (Schumsky, Richman, \& Trinder, 1967), a method was presented for conditioning the eyeblink response as a free operant, employing a double-blind yoked-control procedure. The results of that experiment yielded a high level of conditioning with experimental Ss. In addition, yoked-control Ss showed a marked tendency to reduce the number of eyeblinks through the conditioning period, with an observed return to previous operant levels during the extinction period. Two potential explanations of this latter

* The final draft of this paper was prepared while the senior author was a Special Postdoctoral Fellow at the Center for Research in Human Lear.:ing, University of Minnesota. Partial support was provided by grants to the Center from ise National Science Foundation (GB-17590), the National Institute of Child Health and Human Development (HD-01136 and HD-00098), and the Graduate School of the University of Minnesota.

+Now at the Department of Psychiatry College of Medicine, University of Cincinnati, and Veterans Administration Hospital, Cincinnati, Ohio.

+Now at Wake Forest University, Winston-Salem, N.C. 27106 finding were offered. The first was a conditioning explanation. The second involved the suggestion that employing a visual signal as reinforcer led to less blinking in order to "maintain unhampered vigilance." The present experiment was intended as a replication and extension of the previous one (Schumsky et al, 1967). As before, Ss were run in pairs in the double-blind yoked-control procedure. In order to evaluate whether or not the visual signal per se produced the reduction in eyeblinks noted with previous yoked-control Ss, an auditory or a visual signal was used as reinforcing signal.

Another consideration from the previous paper involved the role of the S's verbal reports of "awareness," as conditioning. The research indicated much higher levels of conditioning for "aware" Ss. Nevertheless, a significant conditioning effect was also obtained for the "nonaware" Ss. The data on which such awareness judgments were made involved a simple question: asking Ss if they knew "what was happening." In view of the they related to their level of implications of such awareness data upon views which require $\mathrm{S}$ awareness for conditioning to take place ( $\mathrm{cf}$. Spielberger, 1962), the present study reconsidered the issue, employing a questionnaire like that previously used by Spielberger \& Levine (1962) in the verbal conditioning context.

\section{METHOD}

The Ss in this experiment were 96 male undergraduate introductory psychology students who were participating in the experiment in order to fulfill a course requirement.

The general procedure employed was essentially like that in the previous Schumsky et al experiment. Ss were run in pairs, each pair including a conditioning $\mathbf{S}$ and his yoked control. The Ss were told that they were in a competition for points and that the experimental problem was for them to figure out what it was they had to do to earn a point. The two Es counting S's eyeblinks had no preexperimental knowledge as to which $S$ was the conditioning $S$, thus effecting the double-blind aspect of the experiment. Reinforcements (points) were administered to both $\mathrm{Ss}$ when the experimental $\mathbf{S}$ blinked his eye. The nature of this reinforcement constituted the major independent variable of the experiment. All Ss throughout the experimental session wore a set of earphones. They were told that when they earned a point they would either hear a tone through the earphones or see a light flash to signify the earning of a point. Randomly, half of the experimental pairs were administered either light or tone reinforcement.

A one-way-vision screen was used to prevent $S$ from seeing $E$ throughout the course of the conditioning phase of the experiment. In the previous experiment, $S$ could see the $\mathrm{E}$ who was counting his eyelid responses, although he was unable to see either the $\mathrm{E}$ administering reinforcement or the yoked $S$ and his respective $E$. Experimental instructions were administered on a face-to-face basis by one $\mathrm{E}$ (the senior author). The Ss were informed that they were in front of a one-way-vision screen and that there was an E counting (true) and signaling earned points (not true) for each of them. Postexperimental interviews were conducted on a face-to-face basis with each $S$ interviewed by his own paired E-counter. A partition prevented Ss from seeing each other. Partitions on the $E$ side of the apparatus also prevented Es from seeing each other. The Es counting responses could see one $\mathrm{S}$ only. The $\mathrm{E}$ administering reinforcement could see both Ss.

In addition to the instruction period and the postexperimental interview, 